\title{
Oloniti e o castigo da festa errada: relações entre mito e ritual entre os paresi*
}

\author{
Renata Bortoletto Silva \\ Mestre em Antropologia Social pelo IFCH/ \\ UNICAMP e doutoranda em Antropologia So- \\ cial pela FFLCH/USP.
}

Artigo aceito para publicação em 12/07/05 resumo Este artigo se propóe a realizar um exercício etnográfico envolvendo a descrição de um ritual intercomunitário conhecido como oloniti, que coletamos entre os Paresi, grupo Arawak do Brasil Central. O exame do ritual, em especial por sua relação de simetria e inversão com o mito denominado $O$ castigo da festa errada, também oriundo dos Paresi, permite desvelar certos códigos que governam as relaçôes sociais, códigos estes que contêm, a um só tempo, valores como a reciprocidade e a predação. Apesar de seu caráter mais marcadamente etnográfico, acreditamos que esse caso, ora analisado, possa vir a contribuir para uma reflexão teórica feita hoje na Etnologia Sul-Americana sobre o lugar da parceria e da guerra para os povos da região.

palavras-chave relaçóes entre mito e ritual, índios Paresi, reciprocidade, predação.

\section{Introdução}

Os Paresi falam uma língua da família Arawak e somam uma populaçáo de cerca de mil indivíduos (OPAN 1996). Eles serão aqui chamados Paresi, termo que, embora não corresponda a uma autodenominação, é veiculado na literatura etnográfica pelo menos desde o século XVIII, quando ocorreram os primeiros

* Quero agradecer a Stela Abreu, Marcio Silva e João Dal Poz pela leitura minuciosa e pelas valiosas sugestốs ao texto. abstract This article is an ethnographic exercise intending to describe an intercommunity ritual known as oloniti, that we collected among the Paresi, an Arawak group of Central Brazil. The study of this ritual, especially regarding its symmetrical and reverse relationship with the so-called myth The punishment of the wrong party, that also originated from the Paresi, allow to watch certain codes that govern social relationships, and such codes consist of values like reciprocity and predation. In spite of its ethnographic aspect, we believe that the case presently analyzed can contribute to a theoretical reflection done at present at South-American Ethnology about the question of war and partnership among the people of this region.

keywords myth and ritual relationships, Paresi indians, reciprocity, predation.

contatos. Eles costumam referir-se a si mesmos como haliti, categoria que possui vários significados, dentre eles "dono" e "gente" (Schmidt 1943: 11; Costa 1985: 50).

Habitantes imemoriais da regiáo sudoeste do estado de Mato Grosso, os Paresi entraram em contato com diferentes e, no mais das vezes, nocivas frentes de expansão, tanto de ordem econômica (mineração, extrativismo), como de ordem religiosa (missóes católicas e protestantes), o que levou o grupo a uma severa depopulaçáo nos primeiros anos de contato. Hoje, sua população 
encontra-se em expansão e está distribuída em trinta aldeias ou grupos locais, freqüentemente localizados ao longo de rios. ${ }^{1}$

Muito embora a bibliografia etnográfica recente sobre os Paresi seja razoavelmente expressiva, estamos ainda longe de ver esgotados temas bastante elementares. Aí, certos aspectos do domínio ritual aparecem muito timidamente diluídos em outros temas como a história de contato e a política indigenista, interesses mais imediatos dessas pesquisas (Costa 1985; Roberto 1994; Costa Filho 1996).

A morfologia social parece caracterizar-se por constantes cisóes dos grupos locais que, por decorrência, apresentam, em sua maioria, pequenas dimensóes e encontram-se dispersos geograficamente por um território relativamente vasto. Apesar disso, as aldeias mantêm um certo grau de integração, sobretudo aquelas de uma mesma origem, ou seja, que são resultado da fragmentação de um único grupo local, e costumam ligar-se por trocas matrimoniais e rituais. Uma das formas de ocorrência de tais associaçóes é o ritual do oloniti, momento em que grupos com laços socialmente distantes se encontram e expressam suas relaçóes. Seu caráter conjuntivo também se expressa simbolicamente, como procuraremos demonstrar neste exercício analítico, de tal modo que valores como a generosidade e a reciprocidade são continuamente evocados durante o ritual. Além disso, o caso paresi pode se tornar um exemplo etnográfico interessante, vindo a contribuir para uma reflexáo bastante atual na Etnologia Sul-Americana sobre o lugar da reciprocidade e da guerra nos esquemas sociais da regiáo (Viveiros de Castro 1986; McCallum 1990; Rivière

1. Estive entre os Paresi nos meses de outubro de 1996 a janeiro de 1997, quando realizei meu trabalho de campo para a pesquisa de mestrado junto ao Programa de Pós-graduação em Antropologia Social pela UNICAMP. Os dados aqui arrolados estão contidos na dissertação de mestrado que resultou dessa pesquisa (Bortoletto 1999).
2001; Fausto 2001), uma vez que o ritual evoca, seja como possibilidade, seja como efetivação, a predação em seu quadro geral. Passemos a ele.

\section{Etnografia do oloniti}

Oloniti é o nome dado à principal festa dos Paresi. Esse é também o termo usado para a bebida fermentada, feita com o polvilho torrado da mandioca brava (Manihot esculenta), servida durante o ritual. A festa é motivada pelos seguintes acontecimentos: nominação da criança, iniciação feminina e cura de doenças. Apesar de ocasióes aparentemente díspares, há algo que une esses momentos, pois em todos eles trata-se de receber um nome, novo no caso do batizado, reforçado no caso da iniciação e da cura.

Assim, o rito tem um papel na produção da pessoa, pois para os Paresi o nome "é o espírito da pessoa" e "serve para dar vida" (Costa 1985: 188). Liga-se ainda à fertilidade da natureza, uma vez que apresenta íntima relação com as fases do ciclo produtivo. Ele é realizado durante a seca, entre os meses de abril e setembro, período de colheita da mandioca e no qual a caça é mais abundante (Rondon \& Faria 1948: 58; Costa 1985: 167; Rowan \& Rowan 1972: 67).

A oferta de comida e bebida em grande quantidade é a condição material da realização do ritual. Já as condições sociológicas e cosmológicas são garantidas pela presença dos convidados que são, via de regra, indivíduos de grupos locais relativamente afastados no cotidiano e, como veremos, simbolizam os espíritos que acedem ao ritual. Tais requisitos podem ser depreendidos na maneira como é feito o convite para as grandes festas de chicha, oloniti kalorecê (kalorecê = grande), ou seja, para aquelas em que concorrem várias aldeias. Depois que os caçadores retornam da caçada, o dono da festa, harekaharé, ou um outro homem da aldeia, sai levando uma corda feita de tucum na qual são feitos nós indicando os dias que faltam 
para o início da festa. Chegando à aldeia a ser convidada, o dono da festa profere, no pátio central, o manati, uma "dissertação histórica ou religiosa que se faz nos festivais" (Rondon \& Faria 1948: 52). Como introdução do convite, é relatado o mito da origem da mandioca, conforme o qual uma menina, aborrecida com o desprezo com que era tratada pelo pai, pede à sua mãe que a enterre no mato. Do corpo da menina surge a mandioca. Depois de contado o mito, assim se expressa o dono da festa:

"Morreu muita ema, muito veado, muito peixe e mais caça ainda", obtendo como resposta do mais velho da aldeia:

"Morreu muita ema, muito veado, muito peixe e mais caça ainda: nós vamos para a festa de vocês" (Pereira 1986: 128).

Aceito o convite, as pessoas arrumam seus pertences e prontamente seguem o dono da festa até a aldeia anfitriá. Chegando lá, a entrada não ocorre imediatamente. Eles permanecem na regiáo que circunda a aldeia e se vestem com roupas especialmente reservadas para essas ocasióes. Mais tarde, os primeiros convidados, apenas os homens, adentram o pátio da aldeia. Dois dentre eles são designados zekáhatihareze, aproximadamente "festeiro malvado" (Costa 1985: 177), e empunham varas compridas com penachos em suas pontas denominadas iohoho, com as quais batem nas casas onde estão as mulheres da aldeia anfitriá: a simulação do ataque cessa com a chegada dos anfitrióes trazendo chicha. Num dos lados da aldeia, juntam-se todos os homens para quebrar o tanohã, duas varas de tamanhos diferentes que são colocadas sobre duas estacas fixas ao chão e rompidas pelos homens com a utilização de seus ombros. As varas quebradas, pintadas com círculos feitos de urucum, são entregues aos donos da festa e levadas em seguida para a casa das flautas, Yámaka, permanecendo ali durante um tempo e depois dispensadas.
Yámaka ou jararaca é, segundo Pereira (1986: 31), o nome dado às flautas secretas, as quais as mulheres não devem avistar. Tais objetos ficam cotidianamente guardados numa casa especialmente construída para elas e denominada yámaka hanã (em que hanã = folha, casa). Ao contrário das malocas paresi, com duas portas voltadas para o nascente e poente, as casas das flautas possuem apenas uma porta, sobre o eixo norte-sul. ${ }^{2}$

Um dos temas que subjaz ao oloniti diz respeito precisamente aos oferecimentos que se faz aos espíritos. Como mencionado, alguns desses espíritos são personificados em instrumentos musicais, tais como yámaka. Essa associação entre instrumentos musicais, em especial os aerofônicos, e espíritos poderosos e perigosos é bastante difundida em grupos das Terras Baixas da América do Sul, sejam eles Arawak ou não. Do mesmo modo a interdição ligada às mulheres também é comum e aparece referenciada pela mitologia com base na posse ancestral que elas tinham do instrumento e lhes foi roubada pelos homens (Piedade 2004: 111-ss).

No ritual do oloniti, além de yámaka, há também xíhali, um outro tipo de flauta que entra também em cena. Ao contrário da yámaka, xíhali fica guardado cotidianamente dentro de casa, não sendo interdito às mulheres. A referida flauta, cujo nome é o mesmo que se dá aos

2. É interessante notar que, embora não sendo Paresi, a interdição foi estendida a mim, o que se verificou também com uma pesquisadora que esteve entre os Waujá, grupo Arawak do Alto Xingu (Piedade 2004). No entanto, Gregor (1982), em seu trabalho entre os Mehináku, os quais também têm restrições a que as mulheres do grupo avistem as flautas, nos faz o seguinte relato: quando mulheres Txicão, um outro grupo xinguano, em visita aos Mehináku, adentraram a casa das flautas, não sofreram a punição esperada, o estupro, segundo os Mehináku, por não serem mulheres do grupo. Desse modo, o fato de ter sido proibida de presenciar a dança com as yámaka indica que, para os Paresi, eu era mulher antes de ser branca, ou seja, ao contrário dos Mehináku, aí prevalece o gênero em detrimento da origem do indivíduo. 
besouros (Coleóptero, indistintamente), uma vez que o formato circular e achatado da flauta lembra o inseto, fica guardada em um bornal pendurado na haste principal da casa. ${ }^{3}$ Ambos, yámaka e xíhali, são instrumentos de posse individual e sua transmissão se dá de pai para filho. Porém, para quem os possui, e também em relação aos parentes próximos do dono, são exigidos oferecimentos cotidianos de carne, beiju e chicha, caso contrário tais espíritos podem trazer malefícios aos seus donos.

Há ainda outros seres para os quais é possível estabelecer relaçóes com oloniti. São os donos de alguns animais consumidos pelos Paresi, tais como o dono das emas e dos veados campeiros, Enoharé (Pereira 1986: 21), e o dono do queixada grande, Ahózay (Pereira 1987: 463). Para esses são feitos oferecimentos cotidianos à porta da casa das flautas, bem como nos rituais.

Se não houver os cuidados regulares para com os espíritos, sejam eles personificados ou não nas flautas, esses podem se indispor com os humanos causando-lhes doenças bem como outros infortúnios. Além dos oferecimentos, há também uma série de tabus a serem obedecidos quando da preparaçáo dessas festas, tais como as interdiçóes sexuais, dentre outras que, se não forem seguidas, podem ocasionar malefícios ao descumpridor e aos seus parentes próximos.

Voltando ao esquema do rito, temos que a quebra de Tanohã é seguida pela entrega das flautas sagradas pelos anfitrióes aos convidados que, por sua vez, deixam a aldeia em direção ao mato. A passagem das Yámaka vem a indicar uma associação, já apontada por outra autora (Costa 1985: 180; 184), entre homens e espíritos que ocorre no ritual. Segundo os Paresi, quem, de fato, participa da festa são os espíritos: eles bebem a chicha, cantam e dançam. Vejamos isso mais de perto.

3. Segundo os Paresi, nem todas as casas têm a flauta xíhali, assim como nem todos os homens têm flauta secreta.

\section{Convidados e anfitrióes}

A entrada das mulheres no ritual nos ajuda a esclarecer melhor a posição de convidados $\mathrm{e}$ anfitrióes na festa. Elas entram na aldeia depois dos homens e são recebidas apenas pelas anfitriâs que as encaminham para os locais onde ficarão as redes. Os homens retornam ao pátio da aldeia onde, empunhando outras varas, novamente atacam a casa onde estão agora todas as mulheres. ${ }^{4}$

Dessa perspectiva, os ataques às casas onde estão as mulheres nos levam a pensar que a clave anfitriáo/convidado pode corresponder a uma outra, de caráter sexual, que opóe mulheres e homens. Como se viu, são todas as mulheres que vão para casa (ocupando a posição de anfitrióes, de dentro), enquanto os homens estão no pátio (na posição de convidados, de fora). Além disso, os anfitrióes levam a chicha para os convidados, desempenhando uma tarefa que é feminina no cotidiano.

Além das questôes de gênero, oloniti imprime também nas relaçóes entre convidados e anfitrióes sentimentos de hostilidade próprios aos afins. O canto chamado Zeratyalo - em que zerati significa cantar (Rondon \& Faria 1948: 70), e cujo nome designa um dos tipos de flauta $^{5}$ - apresenta motivos que evidenciam

4. As convidadas, durante o ataque realizado pelos homens à casa, permanecem ajeitando suas redes e os seus pertences, enquanto as anfitriâs continuam seus afazeres, enchendo os baldes de chicha que os anfitriōes vêm apanhar, dentre outras tarefas. Dito de outro modo, no interior da casa, o clima predominante não é o de temor pelos ataques sofridos da parte dos homens.

5. A informação que me foi dada em campo fazia alusão a quatro tipos de flautas, a saber, amore, tzéyrû, zerátyalo, xíhali. Já Pereira (1986: 31) refere-se a, além destas, outras nove: hiétã, hwerare, txeyxikaharé, imókolo, zoláhî, kaxie, tiryama, ayririkwaré e walalosé. Imókolo, foi dito por um informante ser uma das varas com as quais os homens atacam as casas. Já walalosé corresponde, segundo outro informante, a um momento ritual que ocorre dentro da casa e tem como instrumento musical xíhali, como veremos adiante. Kaxie é também o nome dado à flauta de Pá, Zerô. 
certos conflitos entre sogro e genro. Vejamos então,

\author{
Abandone Uati \\ Meu genro Macaquarece \\ Não tem nada \\ Meu genro preguiçoso \\ Não se vê serviço dele \\ (...) \\ Nem jacaré tem pra comer \\ Eu mesmo cuido de ti \\ Minha filha Cahala. \\ (Rondon e Faria 1948: 78)
}

Essas e outras canções com as yámaka estendem-se até por volta das duas horas da madrugada, quando essas últimas são guardadas na casa das flautas, e os homens ainda de braços dados adentram a casa onde está a chicha. Com a entrada dos homens na casa, as mulheres, que até esse momento descansavam em suas redes, preparam-se para dançar o zolane, termo para o qual não obtive tradução, mas que Rondon $\&$ Faria (1948: 72) e Costa (1985: 183) afirmam tratar-se de um instrumento musical.

A dança cessa nos momentos em que os anfitrióes oferecem bebida e comida aos cantadores e dançadores, precisamente as pessoas que mais bebem durante uma festa. A obrigação de aceitar chicha está embutida na própria designação de convidado, oloniti hoaheré, "aquele que bebe chicha” (Rowan e Rowan 1972: 67; Costa 1985: 170). A chicha (de mandioca e abacaxi) trazida pelos festeiros é bebida em quantidade pelos convidados até provocar o vômito.

Esses oferecimentos, por sua vez, podem apresentar um caráter ambíguo. De um lado, tal obrigação parece ter conotação semelhante àquela dos Wari descritos por Vilaça (1992), para os quais as ofertas constantes de chicha aos convidados até que esses "morram" são tidas como uma vingança pela destruição que provocaram às casas dos anfitriôes. No caso aqui em questão, o mesmo parece se dar, pelo menos num determinado momento, já que, segundo Costa (1985: 181), os festeiros malvados, aqueles que primeiro adentraram a aldeia empunhando as varas com as quais batiam nas casas, bebem mais porque devem ser punidos por terem danificado as casas.

De outro lado, é interessante contrapor aqui um trecho retirado de uma cançáo enunciada quando se fazia a preparação para a festa do Kotitiko. Diziam os cantadores: "estamos cantando bonito, nos dê chicha". Nesse período da preparação apenas participam os co-anfitrióes, além de partes do ritual serem suprimidas, sobretudo aquelas que simulam ataques guerreiros. Parece-nos, assim, que a diferença nos atributos associados à bebida, ora como puniçáo, ora como gratificação, corresponde a diferenças atribuídas aos participantes: para os primeiros, tidos nesse momento como inimigos, a chicha viria a domesticá-los; já para os segundos, parentes próximos, a chicha viria a gratificá-los.

O momento ritual descrito até aqui parece expressar-se, portanto, por uma certa agressividade e, conseqüentemente, caracteriza-se pela potencialidade dos conflitos. Tal caráter tornase mais evidente pelos acontecimentos que descreverei a seguir.

Estes fatos têm lugar apenas durante a primeira noite de execução da dança no interior da casa, num determinado momento em que os cantos que têm como temas certos mitos são substituídos por improvisaçóes que versam sobre fatos do cotidiano, em especial relaçóes extraconjugais ou outros fatos geradores de intrigas e desentendimentos que envolveram a platéia presente, colocando em perigo o convívio social, e que são relatados e discutidos abertamente. ${ }^{6}$ As

6. Assim, à diferença das improvisaçóes que marcam os cantos dos caçadores guayaki, belamente descritos por Clastres (1990), através dos quais esses homens procuram proclamar a sua individualidade, e, portanto, uma afirmação do indivíduo, são a vida em sociedade e os problemas que colocam em risco uma convivência 
atitudes dos convidados para com os anfitrióes a essa altura da festa não se caracterizam pela polidez. Há, por exemplo, inúmeros relatos de brigas ocorridas durante as festas, o que muitas vezes resulta na saída antecipada de um grupo de convidados, antes do fim do ritual.

É ainda durante essa etapa do ritual que os homens deixam a maloca e se dirigem à casa das flautas com alimentos recebidos. Lá, as porçóes são distribuídas entre os ocupantes, que então retornam à maloca, levando nesse instante a flauta denominada xíhali. A referida flauta, cujo nome é o mesmo que se dá aos besouros, uma vez que seu formato lembra o inseto, fica guardada em um bornal pendurado no esteio principal da casa. Nos dias de festa, enquanto é tocada, predomina um clima de euforia geral em que os convidados tentam destruir objetos da casa, vomitar sobre a comida, ou ainda apagar o fogo.

Aí, como se referiu um informante, "já é uma questão de bagunça”. Os donos da casa, na tentativa de proteger alimentos e outros pertences, tentam escondê-los do ataque dos convidados. A intenção não é a de consumir tais bens, como ocorre em situaçóes similares descritas para outras sociedades, como em um ritual dos Cinta Larga, grupo Tupi Mondé que habita a porção noroeste do estado de Mato Grosso, relatado por Dal Poz (1991). Entre os Paresi, o intuito é o da destruição de tais bens. De qualquer modo, ambos parecem evocar um potlatch, instituição de troca total descrita por Mauss (1974), em que o ofertante, ao se despojar de todos os seus bens, submete o convidado, que se torna um devedor e deverá retribuir com outro, porém mais considerável do que aquele que recebeu.

No dia seguinte, os homens costumam iniciar um dos dois jogos comumente praticados nas festas paresi: zicunati e tirimore. ${ }^{7}$ Tais disputas

harmoniosa, os temas para os cantos e as improvisaçóes paresi que ocorrem durante a primeira noite do ritual.

7. O primeiro, no qual dois times compostos de três a dez jogadores se enfrentam, tem como objetivo evitar apresentam um caráter fortemente ritualizado e, por essa razão, devem ser distinguidas de outras modalidades, como os campeonatos de futebol, de que também participam os Paresi, ${ }^{8}$ uma vez que nos confrontos rituais as equipes devem se enfrentar até que ambas tenham obtido a vitória (Costa 1985: 408; Machado 1994: 102). Podemos, inclusive, fazer um contraponto dos jogos rituais com as partidas de futebol que acontecem entre as aldeias.

Assim, a diferença entre as partidas de futebol e os jogos tradicionais pode ser melhor esclarecida ao recorrermos às sugestóes feitas

que a bola feita de mangaba caia no chão, utilizando para isso a cabeça. Ganha aquele que conseguir lançar três bolas no campo adversário, um retângulo traçado no pátio da aldeia. Já tirimore, do qual participam duas equipes ou apenas dois indivíduos, consiste em arremessar manualmente uma bola de marmelo com o objetivo de atingir duas estacas de arame fincadas no solo e sobre as quais espetam-se dois grãos de milho. Os jogadores posicionam-se a cerca de dez metros das estacas que devem acertar. Muito embora os jogos aconteçam nas festas, eles não estáo circunscritos apenas a essas ocasióes. Para que um jogo de bola de cabeça ocorra, basta que uma aldeia convide outra que, por sua vez, não pode recusar o convite, que os Paresi chamam de "desafio" (Costa 1985: 406). Este é o termo usado para descrever a forma como se dão os convites para as lutas entre os Mehináku do Alto Xingu. Um outro ponto comum com os vizinhos xinguanos é que entre esses as lutas não ficam restritas aos rituais, podendo acontecer no cotidiano, quando se enfrentam pessoas de uma mesma aldeia. Já nos rituais, os times que entram na disputa são compostos por pessoas das aldeias anfitriãs contra as dos convidados. Atualmente, as apostas restringem-se aos bens ditos de imoti (branco) - sabão, fósforos, linha, agulha -, mas antigamente apostavam-se arcos, flechas e machados (Faria 1924: 272), ou ainda alguns homens podiam apostar suas irmãs (Costa 1985: 406-ss).

8. Os Paresi realizam em alguns finais de semana, competiçóes semelhantes aos nossos campeonatos, das quais participam equipes de futebol de grande número de grupos locais. Também como nos nossos torneios, lá os times se enfrentam até que o melhor classificado seja considerado vencedor, com direito inclusive a um troféu. 
por Lévi-Strauss (1970b: 54) sobre a distinção entre rito e jogo. $\mathrm{O}$ jogo, por seu caráter disjuntivo, resulta em uma divisão diferencial entre jogadores individuais ou equipes, que náo eram designados, a princípio, como desiguais. No entanto, no fim da partida, distinguir-se-ão em vencedores e perdedores. De maneira simétrica e inversa, o ritual é conjuntivo, uma vez que, de uma diferenciação inicial, institui uma união ao final. Nessa perspectiva, nas partidas de futebol paresi, terminada a competição, os homens voltam às suas respectivas aldeias, alguns como vencedores, outros como perdedores. De modo inverso, percebemos nos "jogos" que acontecem durante um ritual, que terão continuidade em outras ocasióes para que, enfim, terminem "empatado", ou seja, até que os oponentes terminem iguais, como no ritual.

Essa "igualdade" está também relacionada a um outro aspecto desse momento ritual, a saber, à preparação pelas mulheres, a partir da mandioca d'água, do kazalo, em substituição ao oloniti (chicha), não mais ingerido. Kazalo, feito na tarde do segundo dia do ritual, é uma bebida doce servida quente. Ao contrário do oloniti, cuja ingestão exagerada provoca o vômito, kazalo não é ingerido para ser vomitado. Do mesmo modo como afirmou Dal Poz (1991) para uma das bebidas rituais dos Cinta Larga que, por ser bebida exageradamente e provocar o vômito não serve como alimento, o oloniti também possui o caráter de anti-alimento.

Assim, a mudança do tipo de bebida consumida marca, ao meu ver, a distinção entre dois momentos do ritual. O primeiro descrito até aqui, consistiu na chegada dos festeiros, bem como na primeira execuçáo da dança no pátio com as yámaka e da dança na maloca, cujo final culminou com a destruiçáo dos bens dos anfitrióes por convidados "bagunceiros". Uma segunda fase, que já começamos a descrever, tem início com os jogos entre as equipes formadas por anfitrióes e convidados, seguido pelo banho no rio e a nominação, bem como pelas novas execuçóes da dança na casa e com a yámaka. O ponto final dessa segunda fase corresponde aos pedidos de presentes pelos convidados. Vamos a ele.

Já quando os convidados preparam-se para deixar a aldeia, acontece a "dança da formiguinha", "zokó-zokó". Esse termo designa a formigade-fogo ou lava-pés (Solenopsissp). Esse momento, assim como os ocorridos no interior da casa, é marcado por grande descontração. Um ou mais homens convidados colocam-se à porta da casa onde a festa se realizou e, com passos curtos de dança vão e vêm na direção da casa, solicitando roupas, alimentos, fios de linha, animais, assim se expressando textualmente: "A formiga de fogo já vai embora. Ela mora longe e quer alguma coisinha para a viagem" (Roquette Pinto 1950: 346). Os moradores que permanecem dentro da casa depositam, do lado de fora, os presentes no chão e respondem, a cada entrega, de acordo com o que foi pedido. Assim, para oloniti: "Toma o resto da chicha que oferecemos a yámaka".

A referência à formiga nessa parte do ritual parece-me associar-se a uma característica do animal de apanhar e levar nas costas para a casa alimentos que encontre pelo cháo. Os Paresi fazem o mesmo nesse momento ritual e váo para casa carregando os presentes. Além disso, no zokó-zokó que presenciei, o último pedido, proferido num tom de brincadeira ainda maior, tinha como objeto uma criança da casa. Anunciaram o nome da menina e completaram dizendo que ela já estaria grande quando voltassem. ${ }^{9}$ Todos riram, o grupo se desfez e começou a partida.

\section{Mito e ritual}

O percurso seguido na descrição dos passos do ritual procurou evidenciar dois de seus

9. Nesse caso, o rito promove uma inversão da prática social, uma vez que a regra de uxorilocalidade temporária, seguida pelos Paresi, faz com que o homem se mude para a aldeia do sogro e não o contrário. 
momentos que nos parecem distintos e correspondentes a atributos e comportamentos diferenciados que se associam aos convidados da festa. Há um mito, denominado "O castigo da festa errada" (Pereira 1986: 424-26) que, por conter a imagem invertida dos procedimentos considerados corretos no ritual, ajuda-nos a elucidar esses aspectos do ritual. $\mathrm{O}$ mito, em resumo, conta que:

As pessoas de uma aldeia preparavam-se para dar uma festa. $\mathrm{O}$ dono da festa resolveu entáo sair para caçar, enquanto as mulheres ficavam na aldeia preparando a chicha. Seu filho, que vivia sempre junto das mulheres, não quis acompanhá-lo. Quem seguiu o caminho do pai foi sua filha, que estava perto da primeira menstruação. Nesse caminho passou por um morro, uma baixada até chegar ao mato, onde finalmente encontrou o pai. Surpreso com a chegada da menina, o pai a repreendeu pois estava perto da menarca e por esse motivo não deveria estar lá, mas em casa. A menina respondeu que sabia disso, mas quis vir assim mesmo e foram pescar. Foi no rio que a garota menstruou, mas nada disse ao seu pai. Dormiram à beira do rio. Enquanto dormiam, seres espirituais denominados homens do mato e homens da água foram se aproximando, até que mataram e comeram pai e filha. Depois disso os espíritos, transformados nos humanos que haviam matado, tomaram o caminho da aldeia.

Lá, sabendo da menstruação da menina, sua mãe, que não percebeu que a filha havia se transformado em homem do mato, mandou-a para o quartinho de reclusão. A menina dormia muito e se recusava a tomar banho.

Nos dias seguintes começaram a chegar os convidados. O dono da festa-homem do mato, em vez de fazê-lo ele mesmo, mandou que os outros levassem chicha aos convidados no acampamento da festa. De novo recusou-se a levar chicha para os convidados que tocavam a flauta secreta, assim como não ofereceu carne de caça a eles. Ao invés disso, fumava os cigarros preparados para a ocasiáo. A moça, por sua vez, recusava-se a dançar com os moços.

A um sinal dos espíritos que se apresentavam sob a forma de pai e filha, outros espíritos adentraram a aldeia matando e comendo todos os participantes.

O não retorno dos convidados às aldeias de origem começou a despertar preocupação em seus parentes, que foram tentar descobrir o que acontecera. Então, um espírito lhes falou que todos haviam morrido porque Enoharé mandara os homens do mato e da água matá-los e comê-los, como punição a alguns fatos ligados à festa como a menina ter sua primeira menstruação no mato e homens e mulheres terem relaçóes sexuais durante a preparação da bebida fermentada.

O mito acima descrito contém várias passagens do ritual paresi de iniciação feminina, só que os apresenta de maneira invertida ao modo como deveriam ocorrer. Senão vejamos.

Em relação aos procedimentos correspondentes à fase de preparação do ritual, a menina deve permanecer em reclusáo, tendo contato apenas com a mãe e a irmá do pai até que chegue a sua primeira menstruação. Sua saída do quarto, onde esteve reclusa, só ocorre durante o segundo dia do ritual quando, acompanhada por dois rapazes, corre em direção ao rio para banhar-se. Posteriormente, a inicianda participa da festa, devendo dançar com os rapazes, numa atitude de plena disposiçáo para com os convidados. Esses últimos, durante a festa, devem fartar-se de bebida, servida insistentemente pelo dono da festa. Por fim, os convidados pedem presentes aos anfitrióes, para só depois irem embora.

Por sua vez, o mito, como para anunciar um conjunto de inversóes que vão se suceder, tem início com um absurdo, não apenas do ponto de vista do ritual como da própria vida social, ao relatar que uma moça menstrua no 
mato quando deveria estar em reclusão, e que o irmão não acompanha o pai na caçada, ficando com as mulheres na aldeia. Além disso, quando pai e filha voltam, "homens do mato", na verdade, escapam às suas obrigaçóes de doadores em relação aos convidados, receptores.

$\mathrm{O}$ interesse da Etnologia pelas relaçóes entre mito e ritual remonta a Durkheim e Malinowski, dentre outros importantes autores, mas é apenas a partir de Lévi-Strauss que tais relaçóes deixam de ser tomadas unicamente como redundância. Conforme nos mostra Lévi-Strauss (1970a: 255) ao comparar um mito Pawnee com ritos dos Mandan e Hidatsa, povos das planícies norte-americanas, essa relação não se funda em uma espécie de causalidade mecânica, mas no "plano de uma dialética acessível somente sob a condição de ter, previamente, reduzido ambos a seus elementos estruturais".

É assim também que, no caso paresi, reduzindo o mito "O castigo da festa errada" e o rito de iniciação feminina a alguns de seus elementos estruturais, podemos visualizar então os contrastes encontrados.

Rito: enquanto as mulheres permanecem na aldeia, os homens saem como caçadores.

Mito: enquanto o filho permanece com as mulheres na aldeia, pai e filha tornam-se caça.

Rito: quando entram na aldeia, os convidados transformam-se em espíritos ancestrais.

Mito: quando estão no mato, os homens do mato transformamse em anfitriões.

Rito: anfitriões dão em excesso aos convidados-espíritos ancestrais, que nunca recusam.

Mito: homens do mato-anfitriões sequer fazem oferecimentos aos convidados, que sempre pedem.

Rito: convidados-espiritos ancestrais pedem presentes para levarem, quando saírem da aldeia.

Mito: anfitriões desmascarados trazem outros homens do mato para dentro da aldeia, a fim de devorarem os convidados.

Tais contrastes, flagrados na comparação entre mito e ritual merecem alguns comentários: em primeiro lugar, o mito, pela imagem invertida que fornece, chama a atenção para a importância dos oferecimentos para o bom desfecho da festa. Como vimos, no oloniti, as atitudes dos convidados, a princípio pouco amistosas, vão sendo modificadas. $\mathrm{O}$ motor de tal transformação nos parece ser a bebida, posto que ela é servida sobretudo nos momentos em que os convidados se mostram mais perigosos: quando tentam destruir a casa com as varas e no momento em que, já no seu interior, tentam destruir tudo o que nela se encontra. Além disso, quando os convidados vão adquirindo boas maneiras, já no segundo dia do ritual, e começam os jogos que, como observamos, apresentam um caráter conjuntivo, de aproximação entre os participantes, a bebida é substituída: oloniti não será mais ingerido e kazalo, bebida adocicada consumida como alimento no cotidiano, ou seja, nos momentos em que se está entre iguais, passa a ocupar o seu lugar.

A substituição da bebida aparece ainda associada a outras oposiçóes que diferenciam o momento ritual que se inicia. Primeiramente, a ordem das danças é invertida, pois se no primeiro dia a dança com yámaka precede aquela no interior da casa, no segundo, é com a dança no interior da casa que a noite se inicia. Em segundo lugar, durante a dança na maloca já náo acontecem mais as improvisaçóes dos cantos relatando brigas e desentendimentos entre os participantes, bem como não se praticam mais ataques às casas ou aos bens nelas contidos, indicando mudanças nos atributos associados aos convidados.

Nesse sentido, as relaçóes com os convidados, vistas no início sob o signo da inimizade e do conflito, rumam para um final em que o acento é colocado sobre a parceria e a troca entre os grupos envolvidos. Digo isso me amparando no fato de que a continuidade nos rituais é enunciada em vários de seus momentos: nos jogos que terão seqüência até que terminem empatados, no momento da partida, quando se pede uma menina dizendo que virão buscá-la numa ocasião futura, 
ou ainda porque, ao aceitar o convite, o convidado se vê obrigado a retribuir.

Por outro lado, ao aproximarmos oloniti a outros rituais de grupos lingüisticamente aparentados ou geograficamente próximos, percebemos que nesses últimos o próprio ritual encerra uma troca, já que o convidado retribui durante a execução da festa os presentes recebidos, seja levando o peixe, como entre os Enawene Nawe (Silva 1998), seja entregando o artesanato, no caso dos Cinta Larga (Dal Poz 1991). Já no ritual paresi o anfitrião é o único doador: de bebida, comida, roupas, artesanato, dentre outros bens. Porém, assim como aqueles, oloniti também instaura reciprocidade, mas aqui, esta se desenrola em um ciclo longo, com desdobramentos num momento futuro quando houver a retribuição dos presentes, completando um ciclo de troca.

Enfim, o rito parece se constituir em um circuito de trocas diferidas, ou seja, em que as posiçóes de doadores e receptores não são intercambiáveis e que agrega também em si o tema da predação, seja esta como possibilidade, como nos mostra a narrativa mítica, em que a recusa em oferecer leva a um desfecho de guerra e canibalismo, seja efetivamente pelas atitudes dos convidados que pedem o tempo todo, chegando a destruir bens e alimentos dos anfitrióes.

\section{Referências bibliográficas}

BORTOLETTO, Renata. 1999. Morfologia social paresi: uma etnografia das formas de sociabilidade em um grupo Aruak do Brasil Central. Dissertação de Mestrado em Antropologia. Campinas: IFCH/UNICAMP.

COSTA, Romana M. 1985. Cultura e Contato: um estudo da Sociedade Paresi no contexto das relaçóes interétnicas. Dissertação de Mestrado em Antropologia. Rio de Janeiro: Museu Nacional/UFRJ.

COSTA FILHO, Aderval. 1996. Mansos por natureza: situaçôes históricas e permanência Paresi. Dissertação de Mestrado em Antropologia. Brasília: Departamento de Antropologia/UnB.

CLASTRES, Pierre. 1978. "O arco e o cesto". In A Sociedade contra o Estado. Rio de janeiro: Francisco Alves, pp. 71-89.
DAL POZ, João. 1991. No país dos Cinta Larga: uma etnografia do ritual. Dissertação de Mestrado em Antropologia. São Paulo: PPGAS/USP.

FARIA, João Barbosa. 1924. "Zicunati”. Boletim do Museu Nacional. 1(4): 271-73.

FAUSTO, Carlos. 2001. Inimigos fiéis: história, guerra e xamanismo na Amazônia. São Paulo: EDUSP.

GREGOR, Thomas. 1982. Mehináku: o drama da vida diária em uma aldeia do Alto Xingu. São Paulo: Ed. Nacional; Brasília: INL (Col. Brasiliana 373).

LÉVI-STRAUSS, Claude. 1970a. "Estrutura e Dialética”. In Antropologia Estrutural. Rio de Janeiro: Tempo Brasileiro, pp. 254-63.

1970b. "A ciência do concreto". In O pensamento selvagem. São Paulo: Companhia Editora Nacional, pp.19-55.

MACHADO, Maria F. R. 1994. Índios de Rondon. Rondon $e$ as linhas telegráficas na visäo dos sobreviventes Waimare e Kaziniti, grupos Paresi. Tese de Doutorado em Antropologia. Rio de Janeiro: Museu Nacional/UFRJ.

MAUSS, Marcel. 1978. "Ensaio sobre a dádiva. Forma e razão da troca nas sociedades arcaicas". In Sociologia e Antropologia, vol 2. São Paulo: Edusp, pp. 37-184.

OPAN. 1996. Levantamento de dados do povo Paresi (Banco de Dados).

PEREIRA, Adalberto. 1986. O pensamento mitico do Paresi (primeira parte). Pesquisas, Antropologia. São Leopoldo: Instituto Anchietano de Pesquisas.

PIEDADE, Acácio. 2004. O canto do Kawoká: música, cosmologia e filosofia entre os Waujá do Alto Xingu. Tese de Doutorado em Antropologia Social. Florianópolis: PPGAS/UFSC.

RIVIÈRE, Peter. 2001. "A Predação, a Reciprocidade e o Caso das Guianas". Mana. 7(1): 31-53.

RONDON, Candido. M. \& FARIA, J. B. 1948. Esboço gramatical; vocabulário; lendas; e cânticos dos Índios Ariti (Pareci). Conselho Nacional de Proteção aos Índios. Rio de Janeiro: Comissão Rondon, 78.

ROQUETTE-PINTO, Edgard. 1950. Rondônia. Bibl. Pedag. Bras. 39. São Paulo: Companhia Editora Nacional.

ROWAN, Orland \& ROWAN, Philips. 1972. Dicionário: Parecis-Português e Português-Parecis. Brasília: SIL.

SCHMIDT, Max. 1943. "Los Paressis". Revista de la Sociedad Cientifica del Paraguay. 6(1): 1-294.

SILVA, Marcio. 1998. "Tempo e Espaço entre os Enawene Nawe". Revista de Antropologia. 41 (2): 21-52.

VILAÇA, Aparecida. 1992. Comendo como gente. Rio de Janeiro: ANPOCS/UFRJ Editora.

VIVEIROS DE CASTRO, Eduardo. 1986. Araweté: os deuses canibais. ANPOCS/Zahar. 